\title{
Mário de Andrade e a lição do Modernismo
}

\author{
José de Paula Ramos Jr.
}

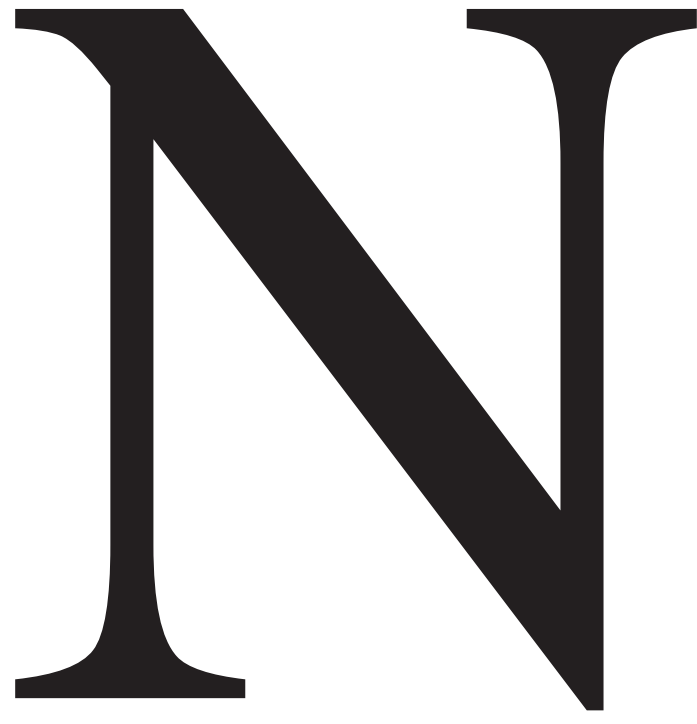

oventa anos passados desde a Semana de Arte Moderna, o que diria Mário de Andrade sobre o movimento que, segundo sua própria avaliação, mudou o Brasil e que, segundo se diz, está morto? Jamais saberemos. Mário, há muito tempo, tornou-se pai de vivos, tal como o herói Macunaíma, e brilha inútil no céu. Porém, é possível imaginar que ele confirmasse o óbito, reafirmando o que dissera na célebre conferência "O Movimento Modernista".

Esse ensaio, de 1942, parte de um histórico do Modernismo para chegar a uma 
avaliação de seu legado para a arte e para a cultura nacional. Observando mais de perto o texto, constata-se que ele pode ser dividido em quatro partes notáveis. A primeira, com valor de introdução, define o movimento como "o prenunciador, o preparador e por muitas partes o criador de um estado de espírito nacional” (Andrade, 1974a, p. 231) e considera os primeiros modernistas "altifalantes de uma força universal e nacional muito mais complexa que nós. Força fatal, que viria mesmo" (p. 231). Entende-se essa "força fatal" como a expansão do mundo industrial moderno, que, no início da década de 1920, já atingira o Brasil, impondo "a criação de um espírito novo" e exigindo a "reverificação e a remodelação da inteligência nacional" (p. 231).

A segunda parte evoca a história do Modernismo. Ao narrar a constituição do movimento, o autor assinala a formação de um "grupinho de intelectuais paulistas" (p. 232), que transitara da pré-consciência à convicção de uma arte nova, primeiramente revelada pela exposição da pintora Anita Malfatti em 1917. Fechando o foco em sua experiência pessoal, Mário de Andrade se refere às suas "leituras desarvoradas" (p. 233) de autores futuristas e à descoberta do poeta belga Émile Verhaeren (1855-1916), especialmente de Les Villes Tentaculaires (1895), obra que o levara a conceber "um livro de poesias modernas, em verso livre, sobre a minha cidade [São Paulo]” (p. 233). Revela, então, o episódio da briga doméstica deflagrada pela Cabeça de Cristo, de Victor

1 Desse ponto em diante, as citações do ensaio "O Movimento Modernista" virão, no fluxo do texto, simplesmente acompanhadas do respectivo número de página, entre parênteses, da edição citada.
Brecheret, "gatilho que faria Paulicéia Desvairada estourar" (p. 233). A família, ao ver o bronze nada convencional de Brecheret, indignou-se, armou celeuma e provocou a fúria seminal de Mário de Andrade. Assim, de modo anedótico, desenha-se o choque do velho espírito acadêmico contra o novo espírito, que se objetivaria coletivamente na Semana de Arte Moderna, entendida como marco do movimento que "foi uma ruptura, foi um abandono de princípios e de técnicas consequentes, foi uma revolta contra o que era a Inteligência nacional" (p. 235).

Voltando ao discurso generalizante, o autor admite que, no primeiro momento, "o espírito modernista e as suas modas foram diretamente importadas da Europa" (p. 236). Rejeita, embora, as acusações de antinacionalismo e antitradicionalismo. Polemicamente, pondera que o Modernismo só se poderia realizar em São Paulo, pois, "pela sua atualidade comercial e sua industrialização, [encontrava-se] em contato mais espiritual e mais técnico com a atualidade do mundo" (p. 236).

Mário de Andrade reconhece que "o movimento modernista era nitidamente aristocrático. Pelo seu caráter de jogo arriscado, pelo seu espírito aventureiro ao extremo, pelo seu internacionalismo modernista, pelo seu nacionalismo embrabecido, pela sua gratuidade antipopular, pelo seu dogmatismo prepotente, era uma aristocracia de espírito" (p. 236). Esse espírito aristocrata foi adotado e protegido pela aristocracia paulista tradicional, sintetizada na figura de Paulo Prado, "fautor verdadeiro da Semana de Arte Moderna" (p. 235). A burguesia "não podia encampar um movimento que lhe destruía o espírito conservador e conformista" e "protestou e vaiou" (p. 237). 
O movimento modernista é, então, dividido em três fases. A primeira dura cerca de seis anos e se inicia com a exposição de Anita Malfatti. É o chamado "período heroico", em que um pequeno grupo de modernistas se formava em São Paulo. "Durante essa meia dúzia de anos, fomos realmente puros e livres, desinteressados, vivendo numa união iluminada e sentimental das mais sublimes. Isolados do mundo ambiente, caçoados, evitados, achincalhados, malditos, ninguém não pode imaginar o delírio de grandeza e convencimento pessoal com que reagimos" (p. 237).

A primeira fase se encerra com a realização da Semana de Arte Moderna, “coroamento dessa arrancada gloriosamente vivida" (p. 238). Dá-se, então, o que Mário considera o "período realmente destruidor" (p. 237) do Modernismo. O movimento se concentra nos salões em que a arte moderna era largamente discutida (Rua Lopes Chaves, Avenida Higienópolis, Rua Duque de Caxias e Alameda Barão de Piracicaba). É, também, a fase de descoberta da realidade brasileira.

Nesse período, os modernistas eram atacados e perseguidos pelos burgueses de espírito e pela própria burguesia endinheirada, mas encontravam apoio, decisivo para a imposição do Modernismo, na aristocracia paulista. Tal apoio se nutria de certos valores compartilhados pelo espírito modernista e o espírito da aristocracia paulista: o internacionalismo, a modernidade, o interesse pela cultura brasileira e, especialmente, a gratuidade: "Numa fase em que ela não tinha mais nenhuma realidade vital, como certos reis de agora, a nobreza rural paulista só podia nos transmitir a sua gratuidade" (p. 238). Mas, se essa elite prestigiava o Mo- dernismo, também provocava a dissolução dos modernistas, ao envolvê-los nos "favores da vida" (p. 238). "A aristocracia tradicional nos deu mão forte, pondo em evidência mais essa geminação de destino - também ela já então autofagicamente destruidora, por não ter mais uma significação legitimável" (p. 241). Aqui, Mário se refere ao esgotamento histórico da aristocracia cafeeira, que se encontrava em acelerado estado de decadência.

É insistente a declaração do caráter destruidor do Modernismo, que Mário considera "o seu sentido verdadeiramente específico", nessa fase de sua história. "Destruidor de nós mesmos, porque o pragmatismo das pesquisas sempre enfraqueceu a liberdade de criação" (p. 240).

Mário de Andrade pressupõe que "os movimentos espirituais precedem sempre as mudanças de ordem social” (p. 242) e, assim, vê o espírito "verdadeiramente modernista" como "preparador; o criador de um estado de espírito revolucionário", que redundara na Revolução de Outubro, em 1930. Nesse ano, extinguem-se os salões e o Modernismo entra na terceira fase, de construção, que já não corresponderia ao "verdadeiro Modernismo".

$\mathrm{O}$ que se pode considerar terceira parte da conferência consiste na caracterização das conquistas do movimento modernista. Mário de Andrade reafirma: “[...] o espírito modernista que avassalou o Brasil, que deu o sentido histórico da Inteligência nacional desse período foi destruidor. Mas essa destruição não apenas continha os germes da atualidade, como era uma convulsão profundíssima da realidade brasileira" (p. 242). Segundo Mário, o Modernismo impusera à realidade nacional a "fusão de três princípios fundamentais: o direito permanente à pes- 
quisa estética, a atualização da inteligência artística brasileira e a estabilização de uma consciência criadora nacional" (p. 242). Nada disso era novo: "A novidade fundamental, imposta pelo movimento, foi a conjugação dessas três normas num todo orgânico da consciência coletiva" (p. 242).

O autor, então, põe em destaque cada uma das três normas. Quanto à primeira, Mário observa que, exceto o Romantismo e o Modernismo, "todos os movimentos históricos das nossas artes [...] sempre se basearam no academismo" (p. 243), expressão do colonialismo cultural. Assim como todas as escolas artísticas, o Romantismo e o Modernismo, de início, também se teriam comportado academicamente, com a importação de modelos europeus, mas o espírito revolucionário dessas duas escolas, imbricado nas respectivas formas estéticas, possuiria um conteúdo antiacadêmico, que, no Brasil, haveria resultado, no primeiro caso, na Inconfidência Mineira, na independência política e na formação do "instinto de nacionalidade", nos termos de Machado de Assis não usados por Mário, mas que bem poderiam ser; no segundo caso, o antiacademismo redundara na Revolução de 30, na consciência coletiva da nacionalidade enfim constituída e na negação do colonialismo cultural.

As pesquisas estéticas do Romantismo e do Modernismo, considerados movimentos "necessários" porque teriam valorizado as "fontes do povo", embeberam-se na realidade nacional. No primeiro caso, de modo episódico e mais individualista; no segundo, apesar dos "despautérios individualistas" (p. 243), na forma de um espírito atualizado e orgânico, "que pesquisava já irrestritamente radicado à sua entidade coletiva nacional" (p. 243). Nos dois casos, "o estandarte mais colorido dessa radicação à pátria foi a pesquisa da língua brasileira" (p. 244), sobre a qual Mário de Andrade realiza uma longa digressão. Nesse aspecto, assinala que a diferença entre as duas escolas se encontraria no fato de que, no tempo do Modernismo, a realidade brasileira estava "mais forte e insolúvel que nos tempos de Alencar ou de Machado de Assis" (p. 244), mas a "ausência de órgãos científicos adequados” (p. 244) fizera com que a "verificação de nosso instrumento de trabalho" (p. 244) fosse reduzida a "manifestações individuais" (p. 244), de modo que "hoje, como normalidade de língua culta e escrita, estamos em situação inferior à de cem anos atrás" (p. 245). Não obstante isso, Mário concede que a "radicação de nossa cultura artística à entidade brasileira" (p. 247) compensaria a suposta falha no plano da linguagem.

Segundo Mário de Andrade, o antiacademismo teria levado à fixação da "lei estético-técnica do fazer melhor" (p. 249). Por outro lado, o experimentalismo antiacadêmico, com seu pressuposto de inserção consciente e coletiva da arte moderna no seu lugar social, cultural e histórico, exigiria do artista a responsabilidade de um "diarismo profissional" (p. 246), em que "ficar no aprendido não é ser natural: é ser acadêmico; não é despreocupação: é passadismo" (p. 246).

O espírito antiacadêmico das pesquisas formais se articularia com a "estabilização de uma consciência criadora nacional", entendida como uma conquista do Modernismo que teria ultrapassado o "amadorismo nacionalista" e o "segmentarismo regional" (p. 247). O Modernismo teria conquistado a descentralização intelectual, que encontrara expressão significativa na proliferação de "editoras cultas de província" (p. 248) 
- Globo, Nacional, Martins - e de núcleos culturais como o de Cataguases, em Minas Gerais, entre outras caixas de ressonância espalhadas pelo Brasil, a evidenciar a consolidação nacional da cultura brasileira, que implicaria a noção de uma nacionalidade brasileira enfim constituída, mas sempre em processo de transformação.

O pressuposto da consciência da realidade nacional seria o reconhecimento de uma tradição própria, compartilhada nacionalmente, que expressaria a particularidade do homem brasileiro, portador de uma identidade peculiar: "Não há dúvida nenhuma que nós hoje sentimos e pensamos o quantum satis brasileiramente" (p. 244). O nacionalismo, porém, prestara-se a "muita falsificação", disfarce de um espírito conformista, acomodatício e acadêmico "que não raro tornou-se um porque-me-ufanismo larvar" (p. 244), em tudo contrário ao autêntico espírito modernista, cuja "verdadeira consciência da terra levava fatalmente ao não conformismo e ao protesto" (p. 244).

Retomando a aproximação entre Romantismo e Modernismo, o conferencista assinala que a diferença fundamental desses dois movimentos, em confronto com as outras escolas de arte brasileiras, estaria no fato de que estas seriam "superfacções culturalistas, impostas de cima para baixo, de proprietário a propriedade, sem o menor fundamento nas forças populares" (p. 250), o que indiciaria a base desumana dessas escolas. Já o Romantismo é entendido como um movimento “absolutamente necessário" (p. 250), porque suas pesquisas estéticas possuiriam aquela base popular e humana requerida, identificável, por exemplo, na proposta de "retorno coletivo às fontes do povo" e na criação da ciência do folclore.
Também no Modernismo se apresentariam "essas mesmas bases populares e humanas" (p. 250) cuja presença Mário de Andrade distingue "no verso livre, no cubismo, no atonalismo, no predomínio do ritmo, no superrealismo mítico, no expressionismo" (p. 250) e, de modo especial, no primitivismo. $\mathrm{Na}$ atitude estética representada pelas postulações do primitivismo, o autor vê a possibilidade de se restabelecer a rompida conexão entre arte e vida, mediante o processamento culto dos "instintos e formas funcionalmente populares, que encontramos nas mitologias cíclicas, nas sagas e nos Kalevalas e Nibelungos de todos os povos" (p. 251).

Ainda a propósito do "direito permanente de pesquisa estética", Mário enfatiza que o Modernismo "não era uma estética, nem na Europa nem aqui. Era um estado de espírito revoltado e revolucionário que, se a nós nos atualizou, sistematizando como constância da Inteligência nacional o direito antiacadêmico da pesquisa estética e preparou o estado revolucionário das outras manifestações sociais do país, também fez isto mesmo no resto do mundo, profetizando estas guerras de que uma civilização nova nascerá" (p. 251).

Encerrando a terceira parte do discurso, na divisão que propusemos, Mário de Andrade adverte que a "atualização da inteligência artística brasileira" não se deve confundir com "liberdade de pesquisa estética, pois esta lida com formas, com a técnica e as representações da beleza, ao passo que a arte é muito mais larga e complexa que isso, e tem uma funcionalidade imediata social, é uma profissão e uma força interessada da vida" (pp. 251-252). Mário destaca que "dentro da funcionalidade humana da arte é que o assunto adquire um valor primordial 
e representa uma mensagem imprescindível" (p. 252).

Com essa reflexão sobre a importância da mensagem na arte, Mário retoma a questão das relações entre arte e vida, que sempre ocupou lugar central em seu pensamento, para articular a quarta e última parte da conferência. Nesta, o autor retoma o discurso pessoal como estratégia para encetar uma áspera crítica ao Modernismo. A autocrítica severa não disfarça o intuito de estender a censura a todo o movimento: "Vítima do meu individualismo, procuro em vão nas minhas obras, e também nas de muitos companheiros, uma paixão mais temporânea, uma dor mais viril da vida. Não tem. Tem mais é uma antiquada ausência de realidade em muitos de nós" (p. 252).

Aquela quadra histórica, "integralmente política da humanidade" (p. 255), exigiria uma mudança de comportamento do artista, no sentido de levá-lo a expressar uma "maior revolta contra a vida como está" (p. 253). Se grande parte dos modernistas se acomodara ao nacionalismo conformista e acadêmico, os que mantiveram o espírito verdadeiro do Modernismo - antiacadêmico, inconformista e criticamente enraizado na realidade nacional -, a despeito do esforço para dar a suas obras um caráter combativo, teriam errado o real alvo a ser atacado. Por meio de imagens que evocam a ideia de molecagem ou de diletantismo inconsequente e irresponsável, Mário pondera que, em vez de "pegar a máscara do tempo e esbofeteá-la como ela merece", os modernistas foram "quebrar vidros de janelas, discutir modas de passeio, ou cutucar os valores eternos, ou saciar nossa curiosidade na cultura" ( $p$. 253). A sua obra e a de companheiros de viagem estariam marcadas por aquilo que ele chama de "insuficiência do abstencionismo" (p. 253).

O Modernismo destruidor fora ultrapassado, mas o novo espírito que se formara de seu legado, embora mais atento às dores do mundo, não se livrara daquilo que Mário de Andrade identifica como a razão do engano que amesquinharia a sua obra e, também, a de seus companheiros: o individualismo. Como superá-lo?

Perante os horrores do tempo vivenciado - a ditadura do Estado Novo e da Segunda Guerra Mundial -, "os abstencionismos e os valores eternos podem ficar para depois"; a atitude correta da arte seria a participação decidida no processo de "amilhoramento político-social do homem" (p. 255), prática entendida como "a essência mesma de nossa idade" (p. 255).

Mário de Andrade considera que o Modernismo não deveria ser um exemplo, mas uma lição. A consciência crítica dos problemas suscitados pelo movimento poderia conduzir a arte à participação no necessário processo de "amilhoramento" do homem, missão que o autor estende às ciências e aos ofícios.

Mário encerra seu discurso transbordando da arte para a política explícita, valendo-se até mesmo de linguagem panfletária "Marchem com as multidões" (p. 255), diz ele para, em seguida, vaticinar a vitória da liberdade sobre as forças que a cerceavam: "A vida humana é que é alguma coisa a mais que ciências, artes e profissões. E é nessa vida que a liberdade tem um sentido, e o direito dos homens. A liberdade não é um prêmio, é uma sanção. Que há de vir" (p. 255).

A nota política final da conferência contém uma implícita, embora veemente, conde- 
nação do regime político em vigor no Brasil naquele momento, a ditadura do Estado Novo, que de certo modo patrocinava o evento. Afinal, a conferência foi realizada na biblioteca do Ministério das Relações Exteriores, no Rio de Janeiro, em 1942, em celebração dos 20 anos da Semana de Arte Moderna.

A efeméride da primeira década modernista passara em branco, como Mário de Andrade assinala na abertura do ensaio "Luís Aranha ou a Poesia Preparatoriana", de 1932: "Faz dez anos que se realizou em São Paulo a Semana de Arte Moderna. Ninguém celebrou essa data e não era mesmo possível celebrá-la" (Andrade, 1974b, p. 47). Na avaliação do autor, além dos participantes da Semana, poucos seriam capazes de aceitar as conquistas modernistas naquele momento. Todavia, a conferência de 1942, nas circunstâncias em que se deu, serve de emblema para a assimilação oficial do Modernismo, no momento em que seu esgotamento era assinalado por um de seus representantes máximos.

Mário de Andrade envolvera-se passionalmente na produção do texto da conferência, arrebatado por um estado de angústia que o atormentara desde o convite para pronunciá-la até muito tempo após proferi-la. Há na correspondência de Mário várias alusões à inquietude sentida nos pródromos do evento, realizado em 30 de abril e presidido por Carlos Drummond de Andrade, na condição de representante do ministro da Educação, Gustavo Capanema. Na condição de amigo, Drummond cita trechos de duas cartas de Mário a Newton Freitas, que ajudam a compor o quadro. Datada de 21/3/1942, a primeira diz:

“[...] estou todinho entregue a uma conferência que aceitei fazer no Rio, na Casa do
Estudante, sobre o Movimento Modernista de 22 , vinte anos passados. Aliás é pretexto pra dizer umas coisas muito brabinhas, tou com certo receio do que vai suceder. Principalmente se tiver pessoas 'oficiais' na conferência. Enfim será o que Deus quiser" (Andrade, 1982, p. 201).

Na segunda, de 8/4/1942, lê-se:

"Estou com o pé no estribo do avião (será estribo?) voando pro Rio, onde vou fazer uma conferência sobre o Movimento Modernista... Não fiz nenhum estudo crítico do movimento, nenhuma análise. Recordei coisas e dessas coisas, com os meus sentimentos de agora, saíram conclusões que nem eu mesmo esperava e umas confissões bastante cruéis" (Andrade, 1982, p. 201).

Em 20/3/1942, dizia ao amigo Paulo Duarte que a conferência seria "talvez a minha coisa mais discutível e mesmo errada. O que importa é o pretexto para o que quero dizer" (Duarte, 1977, p. 227); e em 20/4, a Manuel Bandeira, Mário revelava: "Agora vou me botar na escritura definitiva da conferência do dia 30 , de que talvez você não goste nada. Ando muito desequilibrado, numa espécie de sofrimento esquisito que não consigo discernir bem" (Andrade \& Bandeira, 2001, p. 662).

O que Mário temia das pessoas "oficiais"? Estaria imaginando represálias políticas? É possível, pois vigorava o Estado Novo e seu discurso se encerrava com uma exortação ao engajamento político e à ação libertária. $\mathrm{O}$ crítico João Luiz Lafetá bem assinalou que o final da conferência "ultrapassa a literatura e penetra na área da ação" (Lafetá, 2000, p. 221), acrescentando que a aparente intenção 
de Mário era a de "fazer com que os problemas políticos do momento fossem discutidos pela juventude, que esta se colocasse frente à situação mundial e tomasse partido ativo" (Lafetá, 2000, p. 222). Não houve retaliação política. Entre as pessoas "oficiais" presentes à conferência estavam amigos como Carlos Drummond de Andrade, que registrou não haver sucedido "nada de anormal, durante a conferência e depois dela, nas repercussões impressas" (Andrade, 1982, p. 201).

Decerto, haveria outro motivo para as apreensões de Mário, e não seria propriamente político, mas artístico, embora impregnado de tensões políticas e éticas, conforme demonstrado por João Luiz Lafetá (2000, pp. 219 e seg.).

No momento em que compunha o texto da conferência, Mário de Andrade se encontrava em seu ápice intelectual, mas, após tantos anos de estudo, de reflexão e de ação, não conseguira resolver numa síntese teórica satisfatória as contradições entre arte e vida, que sempre estiveram no núcleo de seu pensamento e de sua prática, como intelectual e como artista. A razão dessa precariedade talvez se explique pelo choque de sua formação cristã com o seu pensamento social propenso ao marxismo. Conforme a síntese crítica de Telê Porto Ancona Lopez (1972, p. 71):

“[...] toda a trajetória ideológica de Mário de Andrade nos mostra o conflito resultante da ânsia de querer domar seu destino em função do compromisso que escolhe e da importância que dá à participação e à coerência. $\mathrm{O}$ compromisso, que nascera na identificação humanitária de cristão em 1917, continua motivado em grande parte pela mesma identificação, que vai adquirindo com o correr do tempo maior objetividade de análise e maior informação. Pensa ser marxista e pensa ser católico, ao mesmo tempo que reconhece não ser verdadeiramente nenhum dos dois".

Lopez observa que a solução encontrada por Mário de Andrade, para acomodar as contradições entre cristianismo e marxismo, fora a aceitação do ecletismo, inspirado em Jacques Maritain, mas adverte: “[...] a partir de 1943 [portanto num momento bem próximo da conferência], apesar de haver encontrado o caminho justo em Maritain, não o segue e continua em conflito" (Lopez, 1972, p. 70).

Mesmo dilacerado pelas contradições entre materialismo e espiritualismo, Mário de Andrade chegara, já antes de 1942, a uma compreensão crítica da arte como linguagem, que pressupõe o domínio técnico dos materiais, o conhecimento da tradição e o "esforço constante de pesquisa" (Lafetá, 2000, p. 214) da realidade. Para ele, a especificidade da arte está nas formas, criadoras de beleza, mas isso não esgota o fenômeno artístico, que se configura como função social interessada e participante, criadora também de uma humanidade melhor. Para além da estética, a arte implica o imperativo ético de "amilhoramento político-social do homem" (Andrade, 1974a, p. 255).

Ao cravar em fermata essa nota final da conferência de 1942, Mário de Andrade dá a seu depoimento o inequívoco caráter político já assinalado, que não deve ser confundido com uma suposta postulação de arte engajada, que nem arte seria se os pressupostos estéticos fossem subsumidos na práxis política. Ao contrário, na arte socialmente interessada de Mário, os pressupostos psicológicos, sociais, culturais, éticos e políticos é que deveriam ser incorporados e elabora- 
dos esteticamente, de modo que a realidade exterior se tornasse interior da obra de arte. Porém, Mário de Andrade considerava deformadora da pureza artística essa inclusão da exterioridade. Em suas próprias palavras, "não há dúvida nenhuma que o assunto não tem a menor importância para a inteligência estética" (p. 252); mas aquele compromisso ético sempre pressuposto conduz o autor à valorização da funcionalidade social da mensagem: "Deformei, ninguém não imagina quanto, a minha obra [...]. Mas eu decidira impregnar tudo quanto fazia de um valor utilitário, um valor prático de vida, que fosse alguma coisa mais terrestre que ficção, prazer estético, a beleza divina” (p. 254).

Em síntese, a conferência de 1942 estuda o movimento modernista segundo a convicção de que a "inteligência estética" se expressa por meio da arte, entendida na condição de fenômeno estético e de função social interessada e eticamente comprometida, sendo que os polos dessa dualidade mantêm uma relação contraditória, teoricamente não resolvida (Bosi, 1972, p. 33).

A angústia sentida por Mário de Andrade em relação à conferência é, sem dúvida, matizada por inúmeras razões, algumas talvez tão íntimas que jamais as conheceremos. No entanto, é evidente que a inquietude derivava sobretudo de sua preocupação com o papel da arte, do artista e do intelectual perante os horrores do mundo em guerra e do sequestro da liberdade no Estado Novo brasileiro. Discorrer sobre o movimento modernista foi, como vimos, "pretexto pra dizer umas coisas muito brabinhas", divulgar conclusões inesperadas e "confissões cruéis", resultantes de "nenhum estudo crítico do movimento, nenhuma análise", mas da recordação do passado misturada com "os meus sentimentos de agora". Não é bem isso o que se verifica na leitura atenta da conferência. Trata-se, propriamente, de um ensaio em que a nota pessoal, a divagação, o dado de memória, a intuição, os afetos e paixões se relacionam com a razão crítica. Há, sim, estudo e análise, que se apresentam misturados aos sentimentos pessoais do autor naquela quadra. A articulação do raciocínio crítico manifesto com a expressão de afetos (ou desafetos) é construída segundo o método digressivo, num esforço de compreensão nascido daquele "sofrimento esquisito", que Mário de Andrade não conseguia "discernir bem", mas que pode ser associado ao senso de compromisso transparente em toda a sua obra.

Decerto, Mário de Andrade viu na celebração oficial dos 20 anos da Semana de 22 a institucionalização do Modernismo, e percebeu o paradoxo dessa situação, que representava a vitória oficial e, também, a decretação oficial do fim do movimento.

A conferência é um esforço de entendimento desse paradoxo, no momento em que as conquistas modernistas se diluíam em novos caminhos ou eram negadas por correntes literárias que se articulavam segundo condições diversas daquelas em que o movimento se desenvolveu. E a consciência crítica dos perigos implícitos nessas tendências artísticas em ação - academismo e conformismo -, gestadas no interior do próprio Modernismo, dava a Mário de Andrade (1974c, p. 171) um sentimento de medo. Daí o empenho com que se lançou à tarefa de, por meio da história do Modernismo, da caracterização de suas conquistas para a cultura nacional e da crítica ao movimento, articular uma lição que pudesse orientar as novas gerações perante o abismo que se abria à sua frente. 


\section{BIBLIOGRAFIA}

ANDRADE, Mário de. "O Movimento Modernista", in Aspectos da Literatura Brasileira.

5 a ed. São Paulo, Martins, 1974a.

"Luís Aranha ou a Poesia Preparatoriana", in Aspectos da Literatura Brasileira.

5a ed. São Paulo, Martins, 1974b.

"A Volta do Condor", in Aspectos da Literatura Brasileira. 5a ed. São Paulo,

Martins, 1974c.

A Lição do Amigo: Cartas de Mário de Andrade a Carlos Drummond de Andrade, Anotadas pelo Destinatário. Rio de Janeiro, José Olympio, 1982.

ANDRADE, Mário de; BANDEIRA, Manuel. Correspondência Mário de Andrade \& Manuel

Bandeira. Organização, introdução e notas de Marcos Antônio de Moraes. $2^{2}$ ed.

São Paulo, Edusp/IEB, 2001.

BOSI, Alfredo. "O Movimento Modernista de Mário de Andrade", in Colóquio / Letras, no 12. Lisboa, Calouste Gulbenkian, 1972.

DUARTE, Paulo. Mário de Andrade por Ele Mesmo. 2a ed. São Paulo, Hucitec, 1977.

LAFETÁ, João Luiz. 1930: A Crítica e o Modernismo. 2ª ed. São Paulo, Duas Cidades/Editora $34,2000$.

LOPEZ, Telê Porto Ancona. Mário de Andrade: Ramais e Caminho. São Paulo,

Duas Cidades, 1972. 